\title{
Fast Vertical Handover Algorithm for Vehicular Communication: A Holistic Approach
}

\author{
Sourav Dhar, Shubhajit Datta, Rabindra Nath Bera \\ Department of E\&C Engineering \\ Sikkim Manipal Institute of Technology \\ Majitar, Sikkim, INDIA- 737136 \\ Email: sourav.dhar80@gmail.com
}

\author{
Amitava Ray \\ Department of Mechanical Engineering \\ Sikkim Manipal Institute of Technology \\ Majitar, Sikkim, INDIA- 737136
}

\begin{abstract}
Next generation vehicular communication environment will consist of heterogeneous radio access networks (RAN). For seamless connectivity, vertical handover is a mandatory requirement. A novel context aware vertical handover algorithm is presented here. TOPSIS (Technique for Order Preference by Similarity to Ideal Solution), which is a multi criteria decision making (MCDM) tool, is used for the development of algorithm and MATLAB/SIMULINK is used as simulation platform. The optimum network is selected, based on multiple factors such as network traffic load, velocity of mobile station, data rate, usage cost and initial delay of network, among the available networks such as WiMax, WLAN and UMTS. This algorithm has been tested by simulating a virtual road traffic scenario. Variations in optimum RAN selection with vehicle speed keeping network traffic load constant and RAN selection with network traffic load keeping vehicle speed constant are shown graphically. The proposed algorithm is very simple yet powerful compared to the existing VHO algorithms and hence requires less execution time.
\end{abstract}

Index Terms - ITS, Vertical handover (VHO), MCDM, TOPSIS, V2V and V2I.

\section{INTRODUCTION}

The primary goal of Intelligent Transportation System (ITS) is to make journey safe and enjoyable by converging remote sensing, communication and information technologies with transportation engineering [1]. Intelligent Transportation Society of America (ITSA), which has collaboration with Association for Intelligent Transport System (AITS) INDIA, aims to improve cooperation among public and private sector organizations. ITSA summarizes its mission statement as "vision zero" meaning its goal is to reduce the fatal accidents and delays as much as possible [2]. Shladover [3] has given a review on recent research progress on highway vehicle automation and indicates the important research challenges that still need to be addressed before highway automation can become an everyday reality. The transportation problem is considered as a social problem in [4] and emphasis given on the fact that by the absence of the ITS people will suffer significant losses in terms of time, health, money and mobility. Implementation of sustainable transport is considered in [5].

Ubiquitous vehicle to vehicle (V2V) and vehicle to infrastructure (V2I) communications are essential for both safety and non safety applications of ITS. To maintain seamless connectivity, vertical handover (VHO) facility should be implemented in next generation communication devices.

In homogeneous networks, horizontal handovers are typically required when the serving access router becomes unavailable due to mobile terminal's movement. In heterogeneous RANs, the need for vertical handovers can be initiated for convenience rather than only connectivity reasons (e.g., according to user choice for a particular service). Implementation of "Always Best Connected (ABC)" concept, of being connected in the best possible way in an environment of heterogeneous RANs, is the major challenge in the design of VHO algorithms [6].

VHO decision problem in vehicular communication has been addressed in this paper. The VHO decision process answers when and where to hand over in a heterogeneous environment on the move. Decision criteria include Quality of Experience (QoE) parameters like user preferences as well as Quality of Service (QoS) parameters like network conditions, application requirements and terminal capabilities. These have to be evaluated and compared to detect and to trigger VHO. In the context of future wireless networks, many analysis, studies and tutorials were proposed in the literature [6-20], but none of these were proposed specific to a transport scenario. We show how advanced tools like TOPSIS (Technique for Order Preference by Similarity to Ideal Solution) as well as proven concepts can be used to solve such a problem and thus answering $\mathrm{ABC}$ requirement. 
The rest of the paper is organized as follows: latest trends in this field and the research gaps are discussed in section II in form of literature review. Section III highlighted the authors' contribution so far in the field of intelligent transportation system. Design approach is discussed in section IV. TOPSIS, which is the principal mathematical tool in the design of this algorithm, has been presented in section V. A case based approach is taken to test the algorithm and the test environment is introduced in section VI. The algorithm design and the simulations are presented in section VII and VIII respectively. Finally the paper is concluded in section IX.

\section{LITERATURE REVIEW}

VHO is the vision of $4 \mathrm{G}[7,8]$. Gustafsson and Jonsson [6] have described the concept of being always best connected, the user experience and business relationships in an $\mathrm{ABC}$ environment, and outlined the different aspects of an $\mathrm{ABC}$ solution that will broaden the technology and business base of next generation communication. A survey on the research issues, challenges, and possible approaches to tackle the ABC challenges for vehicular telematics over heterogeneous wireless networks presented in [9]. Also, an advanced heterogeneous vehicular network (AHVN) architecture, which uses multiple access technologies and multiple radios in a collaborative manner, is outlined here.

A general overview of vertical handover decision algorithms are discussed in [10-12], where as, an overview of vertical handover from the vehicular network (VN) perspective has been described in [13].

Both the received signal strength (RSS) and the velocity of mobile terminal along with usage expenses are considered for $\mathrm{VHO}$ decision algorithm design in [14, 15]. MCDM based decision algorithms are presented in [16-18]. Analytic hierarchy process (AHP) is used as decision making tool in $[16,17]$ whereas TOPSIS is used in [18]. SINR (Signal to Interference plus Noise Ratio), AHP and Entropy weight method based TOPSIS (SAETOPSIS) vertical handoff algorithm is proposed in [18]. Context aware vertical handoff architecture, proposed in $[19,20]$, consists of a context repository and an adaptability manager for network selection.

From the review of the literature, we conclude with the following criticisms:

1) The researchers have not shown the relation of mobile terminal velocity and the optimum RAN selection.

2) The mathematical formulation of vertical handover is rigorous and need longer execution time.

3) Most of the algorithms are tested in two network environments. Validity of the algorithms is not tested for more than three RANs.

4) Impact of network traffic load (NTL) on the optimum RAN selection is not explored.

Thus the principal objective of this work is to design a novel VHO decision algorithm which involves simple mathematical calculation and yet selects the optimum RAN considering multiple criteria. In the present work, we propose a model that analyzes the case in which a vehicle is kept at different positions of a highway, and the network ranking optimizes the "best available network" in multiple constraint environments.

\section{BACKGROUND OF THE WORK}

Authors are involved in the development of multichannel solution for ITS challenges. Remote sensing is used in ITS for safety applications. Authors have shown in [21-24], how digital radar is effective to avoid collision. Ubiquitous communication is another major requirement for both safety and non safety applications. Dynamic Channel modeling and channel estimation are another key issue in ITS and are addressed by the authors in [2528]. Authors have taken an initiative to design a robust vertical handover algorithm to provide seamless connectivity in heterogeneous network scenario [29-31]. Convergence of both remote sensing and communication is presented in [32]. This work is an extension to the work presented in [21-32]. Here, a novel context aware fast vertical handover model is developed and simulated to provide uninterrupted connection for $\mathrm{V} 2 \mathrm{~V}$ and $\mathrm{V} 2 \mathrm{I}$ communication.

\section{DESIGN APPROACH}

Functional architecture of our proposed vertical handover engine (VHO engine) is shown in figure 1. Context warehouse and the VHO manager are the two major parts of the proposed $\mathrm{VHO}$ engine.

The VHO manager holds the responsibility for switching from current RAN to another suitable one. It consists of the main phases of a handover process, viz., handover initiation, Handover decision (i.e., network selection) and Handover execution. Handover initiation is a continuous process of RSS and QoS measurement. If either of these two is found critical then spectrum sensing will be started. If any other RAN is found available (network availability detector is responsible for this work.) then handover process will be initiated else the wireless device will continue the communication through the current radio access network.

To measure the QoS of the current RAN, it is required to have the knowledge of the context information like network availability, RSS (Received Signal Strength) and current network traffic load, speed of the vehicle, battery power, location information, monetary cost of service, service capabilities etc. The Context Warehouse module basically a database which collects all the contextual information, through monitoring and measurements, required to identify the need for handover and to apply handover decision. Since the user has the ultimate say, thus the user preferences are very important parameter for VHO decision. The context warehouse also accepts the inputs from the user. User preferences are basically the type of application (data rate/ bandwidth required) and affordable cost for the service. These data are monitored periodically and updated accordingly. Once the handover process is initiated, the gathered context information in context warehouse will be supplied to the VHO manager. The optimum network will be selected based on TOPSIS 
method. In handover execution phase, the VHO manager will first check whether the selected network is different from the current network. If so, then it will issue a VHO command and will direct the control unit of the wireless device to reconfigure the hardware according to the selected RAN.

\section{TOPSIS}

In this method two artificial alternatives are hypothesized:

- Ideal alternative: the one which has the best level for all attributes considered.

- Negative ideal alternative: the one which has the worst attribute values.

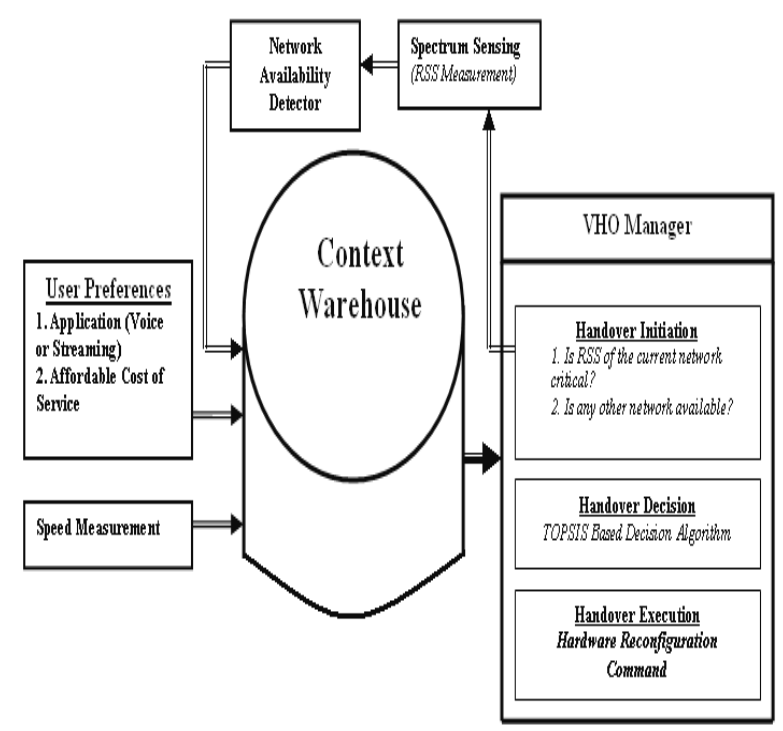

Figure 1. Functional Architecture for VHO Engine

TOPSIS [33] assumes that we have ' $\mathrm{m}$ ' alternatives (options) and ' $\mathrm{n}$ ' attributes/criteria and we have the score of each option with respect to each criterion. TOPSIS based decision method is explained in figure 2. There are two solutions, i.e, ideal solution $\left(\mathrm{A}^{+}\right)$and the negative ideal solution $\left(\mathrm{A}^{-}\right)$. The distances of the alternatives from $\mathrm{A}^{+}$and A-are calculated and TOPSIS selects the alternative that is the closest to the ideal solution and farthest from negative ideal alternative by calculating the closeness coefficient which is a measure of relative closeness to the ideal solution.

Let $\mathrm{x}_{\mathrm{ij}}$ be the score of option $\mathrm{i}$ with respect to criterion $\mathrm{j}$. The score is to be selected from a scale of 1 to 9 .

Now form a matrix $\mathrm{X}=\left(\mathrm{x}_{\mathrm{ij}}\right) ; \mathrm{m} \times \mathrm{n}$ matrix.

Let $\mathrm{J}$ be the set of benefit attributes or criteria (more is better)

Let $\mathrm{J}^{\prime}$ be the set of negative attributes or criteria (less is better)

Now the closeness coefficient is found by evaluating the following steps.

Step 1: Construct normalized decision matrix. This step transforms various attribute dimensions into nondimensional attributes, which allows comparisons across criteria.
Normalize scores or data as follows:

$$
r_{i j}=\frac{x_{i j}}{\sqrt{\sum_{i} x_{i j}^{2}}}, i=1,2, \ldots \ldots . \quad m, j=1,2 \ldots \ldots \ldots
$$

And normalized matrix is, $\mathrm{R}_{\mathrm{ij}}=\left(\mathrm{r}_{\mathrm{ij}}\right)$, $\mathrm{m} \times \mathrm{n}$ matrix.

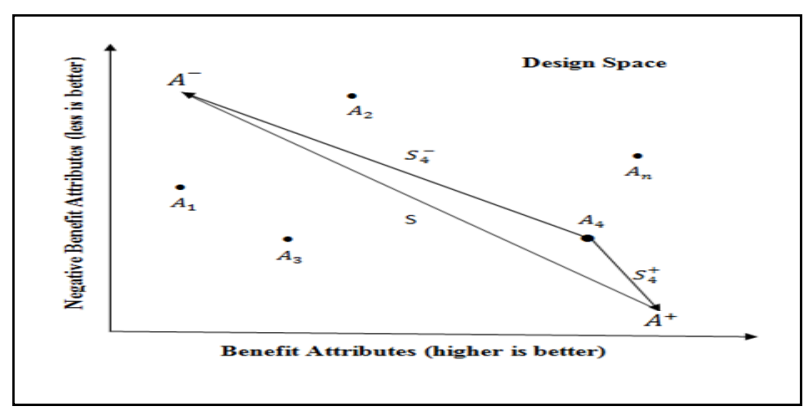

Figure 2. TOPSIS based Decision Method

Step 2: Construct the weighted normalized decision matrix.

Decide a set of weights for each criteria $\mathrm{w}_{\mathrm{j}}$ for $\mathrm{j}=$ $1, \ldots$ n.

Multiply each column of the normalized decision matrix by its associated weight.

An element of the new matrix is:

$$
\mathrm{v}_{\mathrm{ij}}=\mathrm{w}_{\mathrm{j}} \mathrm{r}_{\mathrm{ij}} \ldots \ldots(2)
$$

Step 3: Determine the ideal and negative ideal solutions.

\section{- Ideal solution}

$A^{+}=\left\{v_{1}^{+}, \ldots, v_{n}^{+}\right\}$

Where,

$$
v_{i}^{+}=\left[\operatorname{Max}_{i}\left(v_{i j}\right) \quad \text { if } \quad j \in J ; \operatorname{Min}_{i}\left(v_{i j}\right) \quad \text { if } \quad j \in J^{\prime}\right] \ldots
$$

- $\quad$ Negative ideal solution

$A^{-}=\left\{v_{1}^{-}, \ldots, v_{n}^{-}\right\} \cdots . .(5)$

Where,

$v_{i}^{-}=\left[\operatorname{Min}_{i}\left(v_{i j}\right) \quad\right.$ if $\quad j \in J ; \operatorname{Max}_{i}\left(v_{i j}\right) \quad$ if $\left.\quad j \in J^{\prime}\right] \ldots$

Step 4: Calculate the separation measures for each alternative.

- The separation from the ideal alternative is:

$S_{i}^{+}=\left[\sum_{j}\left(v_{i}^{+}-v_{i j}\right)^{2}\right]^{1 / 2} \quad \ldots$.
for $\mathrm{i}=1,2, \ldots, \mathrm{m}$

- Similarly, the separation from the negative ideal alternative is:

$$
\begin{aligned}
& S_{i}^{-}=\left[\sum_{j}\left(v_{i}^{-}-v_{i j}\right)^{2}\right]^{1 / 2} \ldots \\
& \text { for } \mathrm{i}=1,2, \ldots, \mathrm{m}
\end{aligned}
$$

Step 5: Calculate the relative closeness to the ideal solution 
- The relative closeness to the ideal solution is:

$$
C_{i}^{+}=S_{i}^{-} /\left(S_{i}^{+}+S_{i}^{-}\right) \quad \text { where, } 0 \leq C_{i}^{+} \leq 1 \ldots
$$

Select the option with $C_{i}^{+}$closest to 1 .

\section{CASE STUdy}

Let us consider a virtual road traffic scenario as shown in figure 3. At position A, the vehicle has passed the toll booth and is about to enter in a city. Thus all three radio networks are available here. Point $B$ is almost similar to point $\mathrm{A}$; here the vehicle is in a suburban area. Point- $\mathrm{C}$ is far from city and only UMTS network is available here.

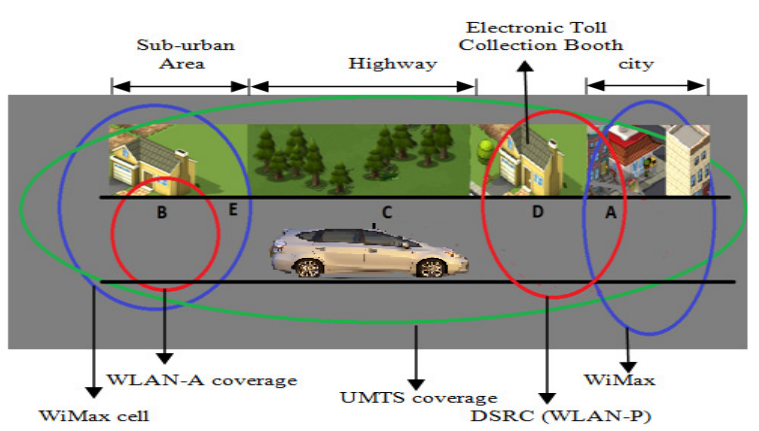

Figure 3. A Typical Radio Network Availability Scenario for ITS

Point-D is near to toll booth, and UMTS along with dedicated short range communication (DSRC) network is available here. Currently, the IEEE standard proposed for DSRC, known as $802.11 \mathrm{p}$, is based upon the IEEE 802.11a standard. DSRC is already in use in USA, Europe and Japan for electronic toll collection. Point- E indicates the suburban area where WLAN network is not available and the vehicle is in the edge of the WiMAX coverage area. Handover needs to take place when either RSS is critical or QoS is poor for current RAN.

As we are considering a transportation system, velocity/speed of the vehicle (mobility) is an important factor that is to be taken into consideration. WiMAX supports the highest mobility among the three and WLAN has the lowest support for mobility and the least coverage area. Another parameter taken into consideration is the Initial delay, which is the setup time for a connection. According to [34], delay could be up to seven seconds for UMTS. WLAN connectivity, on the other hand, is perceived as responding instantaneously. WiMAX response could be faster than UMTS but slower than WLAN.

\section{AlgORITHM DESIGN}

Here the objective is to choose the optimum network out of three given RANs under the road traffic scenario shown in figure 3.

The number of alternatives $(\mathrm{m})=3$

There are five attributes or criteria are taken into consideration: objective factors like Speed of the vehicle, Network Traffic Load (NTL) and subjective factors like Bandwidth, Initial Delay (ID) and Usage Cost (UC).
The number of criteria $(\mathrm{n})=5$

TABLE I. WEIGHTS OF EACH ATTRIBUTES ASSIGNED BY EXPERTS

\begin{tabular}{c|lllll}
\hline Experts & Speed & Bandwidth & NTL & ID & UC \\
\hline E1 & 0.4 & 0.2 & 0.1 & 0.2 & 0.1 \\
E2 & 0.5 & 0.2 & 0.1 & 0.1 & 0.1 \\
E3 & 0.3 & 0.2 & 0.2 & 0.2 & 0.1 \\
E4 & 0.4 & 0.1 & 0.2 & 0.2 & 0.1 \\
E5 & 0.3 & 0.2 & 0.2 & 0.2 & 0.1 \\
E6 & 0.4 & 0.3 & 0.1 & 0.1 & 0.1 \\
E7 & 0.3 & 0.4 & 0.1 & 0.1 & 0.1 \\
E8 & 0.5 & 0.1 & 0.1 & 0.2 & 0.1 \\
E9 & 0.4 & 0.2 & 0.1 & 0.1 & 0.2 \\
E10 & 0.3 & 0.3 & 0.1 & 0.1 & 0.2 \\
Average & 0.38 & 0.22 & 0.13 & 0.15 & 0.12 \\
\hline
\end{tabular}

Here speed of vehicle, bandwidth and network traffic load are benefit attributes whereas initial delay and usage cost are negative benefit attributes. There are 10 experts consulted for assigning the weights to the deferent attributes. Averages of these weights are considered for decision algorithm design (table I). The score of each alternative with respect to the subjective factors can be obtained from the experts whereas the score of each alternative with respect to the vehicle speed (objective factor) can be obtained by using (10). All the scores range from 1 to 9 .

$$
\begin{aligned}
& V_{w l}=9-(\text { speed } \times 8) / 30 \\
& V_{u}=9-(\text { speed } \times 8) / 90 \\
& V_{w m}=9-(\text { speed } \times 8) / 130
\end{aligned}
$$

Where, $\mathrm{V}_{\mathrm{wl}}, \mathrm{V}_{\mathrm{u}}$ and $\mathrm{V}_{\mathrm{wm}}$ are the scores of WLAN, UMTS and WiMAX respectively with respect to the objective factor speed. Similarly for objective factor NTL is scores can be obtained using (11),

$$
\begin{aligned}
& N_{w l}=4-(4 N T L) / 100 \\
& N_{u}=9-(4 N T L) / 100 \\
& N_{w m}=5-(4 N T L) / 100
\end{aligned}
$$

The common term in (11), (4NTL)/100, signifies the uniform distribution (in percentage) of NTL. These scores along with the scores with respect to the subjective factors, as obtained from the experts, are listed in table II. Further the closeness coefficients are found by following the steps described in section V. The network with maximum closeness coefficient value will be the selected RAN.

Where,

$\mathrm{J}=$ The set of benefit attributes or criteria (more is better)

$=[$ Velocity, Bandwidth, NTL]

And,

$\mathrm{J}^{\prime}=$ The set of negative attributes or criteria (less is better)

$=[$ Initial Delay, Usage Cost $]$

TABLE II. SCORE OF EACH ALTERNATIVES WITH RESPECT TO EACH ATTRIBUTES $\left(\mathrm{X}_{\mathrm{IJ}}\right)$

\begin{tabular}{c|lllll}
\hline Weights & 0.38 & 0.22 & 0.13 & 0.15 & 0.12 \\
\hline Alternatives & Speed & Bandwidth & NTL & ID & UC \\
WLAN & $\mathrm{V}_{\mathrm{wl}}$ & 7 & $\mathrm{~N}_{\mathrm{wl}}$ & 1 & 2 \\
UMTS & $\mathrm{V}_{\mathrm{u}}$ & 1 & $\mathrm{~N}_{\mathrm{u}}$ & 9 & 4 \\
WiMAX & $\mathrm{V}_{\mathrm{wm}}$ & 7 & $\mathrm{~N}_{\mathrm{wm}}$ & 3 & 9 \\
\hline
\end{tabular}




\section{Simulation}

\section{Assumptions}

The following assumptions are made for solving the problem which is defined above:

i) Situations of point " $A$ " and point "B" of figure 1 , where all the three RANs are available, are considered for simulation.

ii) Uniform NTL distribution is considered in this work, i.e, all the networks are equally loaded at given instant of time. The UMTS can handle maximum NTL whereas WLAN performance will be satisfactory only for low NTL.

iii) Two types of applications are considered, viz., conversational/ voice communication and streaming applications (audio, video streaming, internet access, data transfer etc.). Each of these applications requires a different bandwidth.

iv) Speed of the vehicle and NTL are objective factors (which can be compared on the basis of measured value) and other influencing (Bandwidth, initial delay and usage cost) factors are subjective factors.

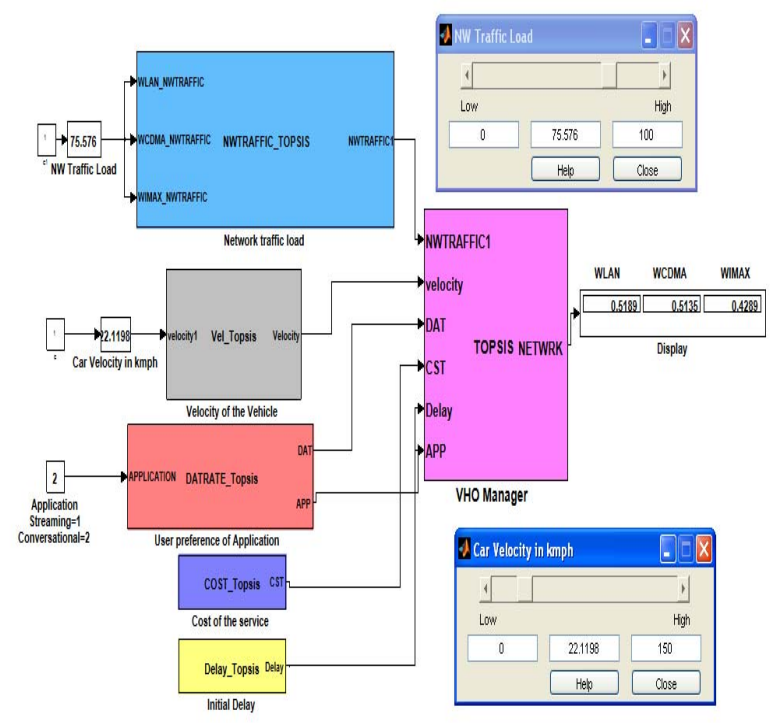

Figure 4. SIMULINK model for TOPSIS based Vertical Handover.

\section{Simulation}

Figure 4 shows the SIMULINK model developed for network selection in vehicular communication using the TOPSIS Method when all the three options are available. Here TOPSIS for individual criteria are calculated and given as input to the decision maker block. Network availability detector block senses the spectrum and decides how many networks are available. As per the problem definition it is considered that UMTS is always available. Thus the network availability detector decides whether WLAN and WiMAX are available or not based on the RSS. Result of this block triggers the other blocks. If a network is not available then it will not be considered as an alternative. Speed of the vehicle and NTL can be altered using a slider and the final ranking will be displayed on the display unit. For conversational application, data rate/ bandwidth does not have much importance but for streaming applications data rate plays a key role. Other TOPSIS matrices are calculated as per the design of TOPSIS method. Finally the decision maker of VHO manager takes a decision following the steps of TOPSIS. A display shows the final ranking of the networks. Network with highest ranking is the selected network.

\section{Results}

The simulation results shown here are analyzed for both categories of traffic. The selection of the RAN differs depending on applications. Here simulation is carried out considering that all the three networks are available. NTL and the speed of the vehicle are varied here. For each network, the relative closeness to the ideal solution (network selection index) is measured keeping either NTL or speed constant. Selections of the optimum network for different scenarios are shown in (Fig. 5Fig.12).

The responses of individual network are also found by varying NTL and speed simultaneously and are shown in 3D plot (Fig. 13-Fig.15).

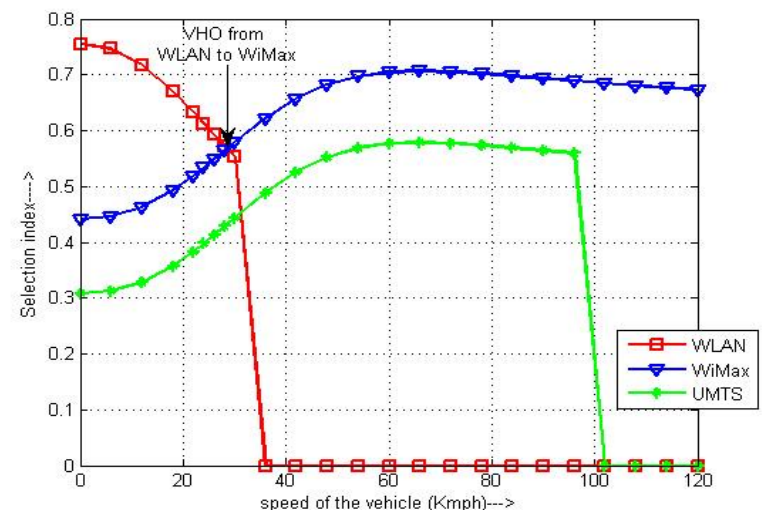

Figure 5. RAN selection index VS speed of the vehicle when NTL is $4 \%$ (for streaming)

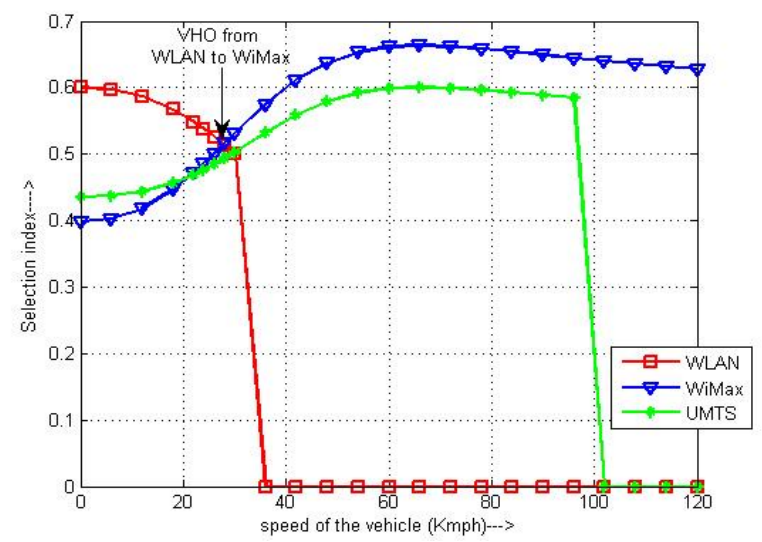

Figure 6. RAN selection index VS speed of the vehicle when NTL is $97 \%$ (for streaming) 


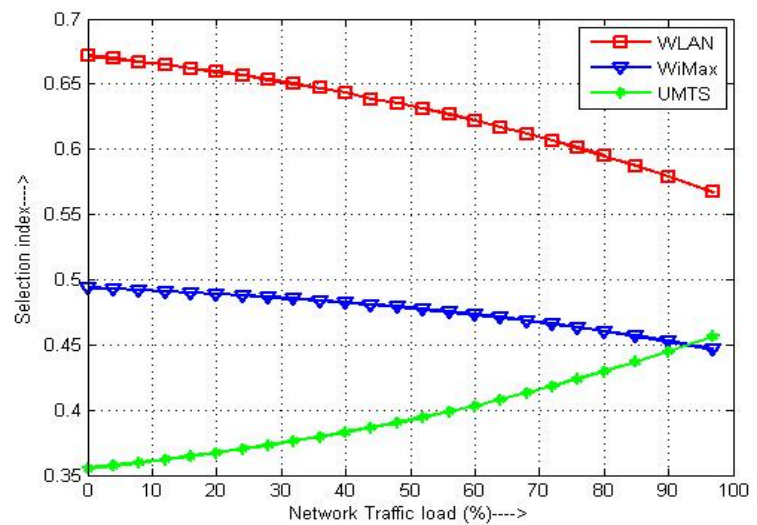

Figure 7. RAN selection index VS NTL (\%) when speed of the vehicle is $18 \mathrm{~km} / \mathrm{h}$ (for streaming)

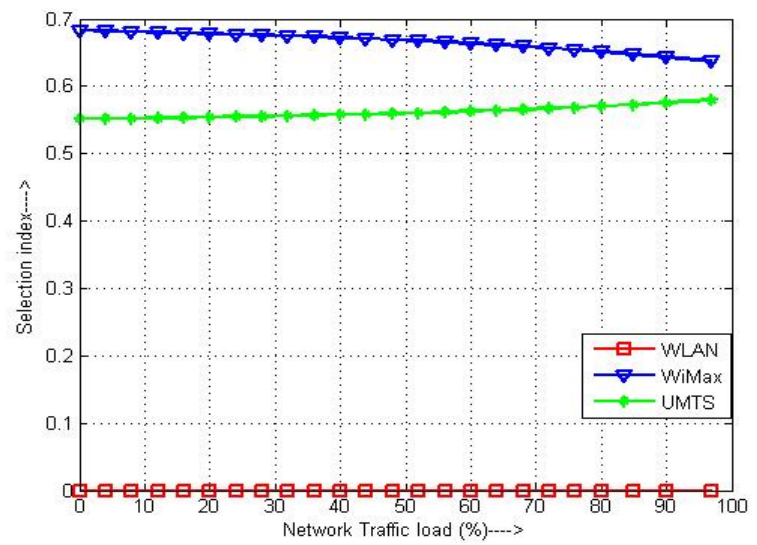

Figure 8. RAN selection index VS NTL (\%) when speed of the vehicle is $48 \mathrm{~km} / \mathrm{h}$ (for streaming)

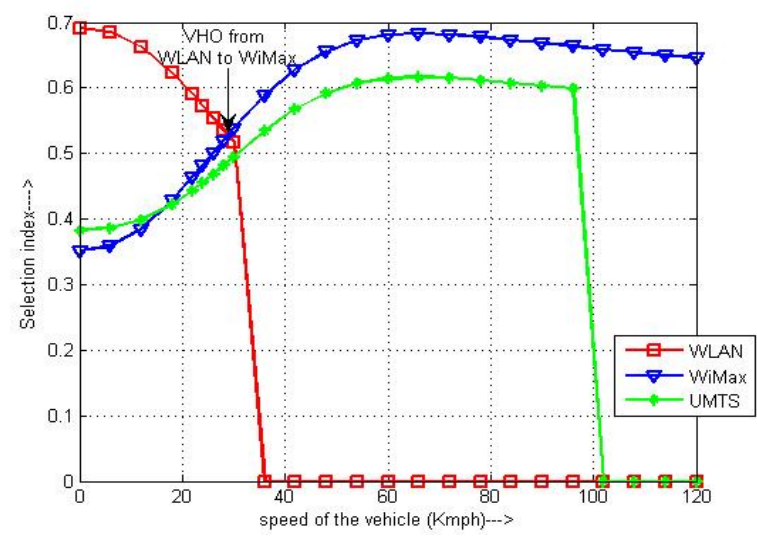

Figure 9. RAN selection index VS speed of the vehicle when NTL is $4 \%$ (for conversational)

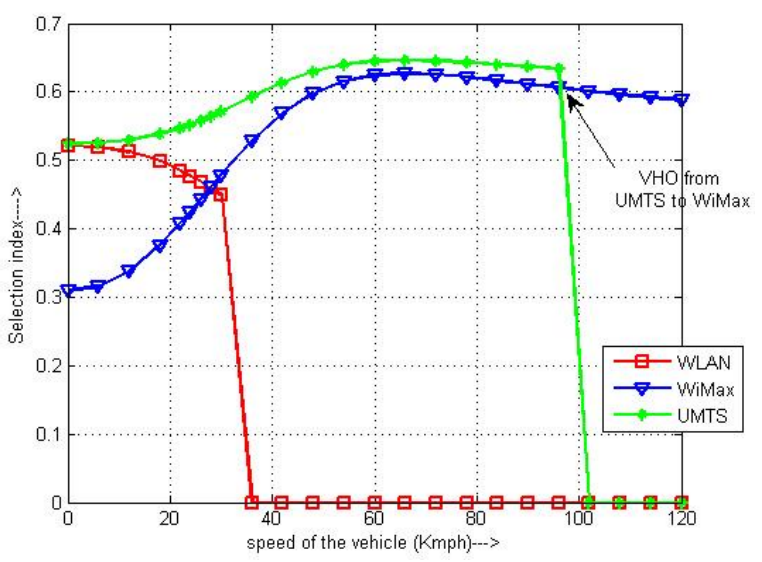

Figure 10. RAN selection index VS speed of the vehicle when NTL is 97\% (for conversational)

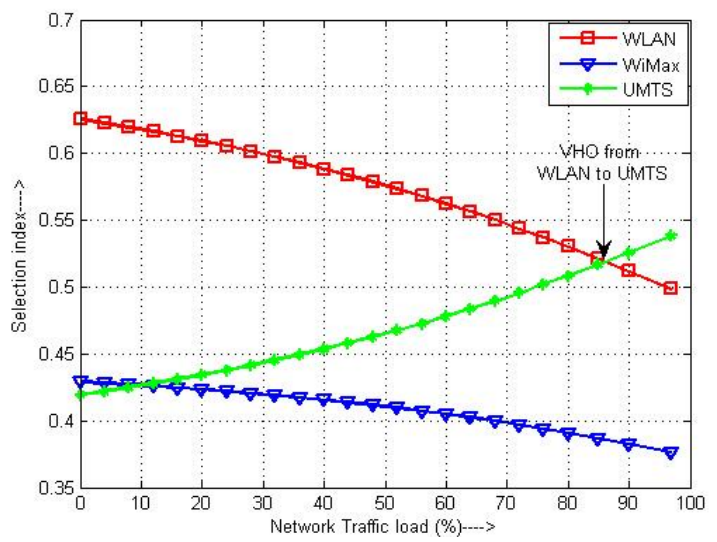

Figure 11. RAN selection index VS NTL (\%) when speed of the vehicle is $18 \mathrm{~km} / \mathrm{h}$ (for conversational)

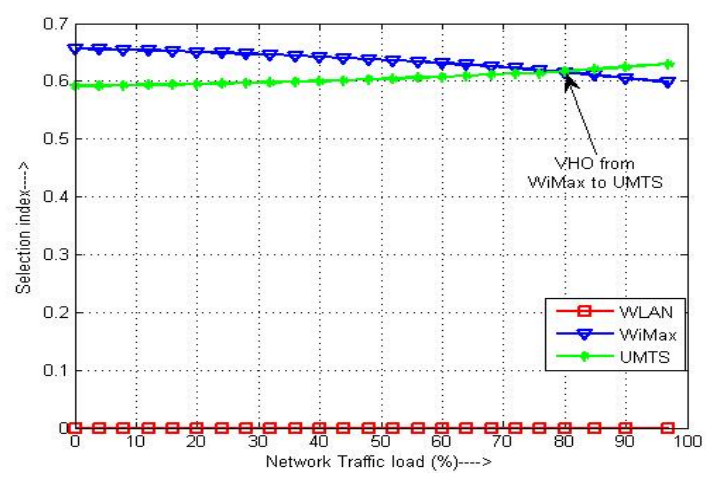

Figure 12. RAN selection index VS NTL load (\%) when speed of the vehicle is $48 \mathrm{~km} / \mathrm{h}$ (for conversational 


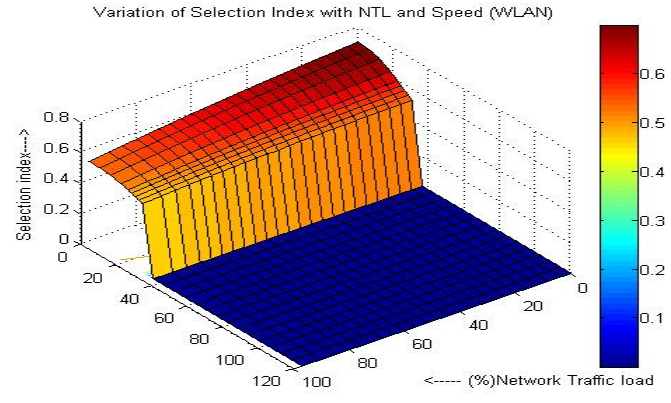

Figure 13. Variation of selection index with NTL and speed (WLAN)

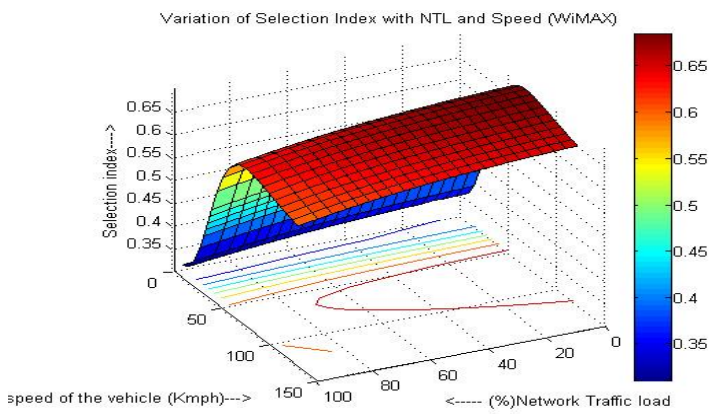

Figure 14. Variation of selection index with NTL and speed (WiMax)

\section{REFERENCES}

[1] H. Leung, N.E.E. Faouzi, A. Kurian, Intelligent Transportation System (ITS), Information Fusion 12 (2011) 2-3, Elsevier; doi:10.1016/j.inffus.2010.06.003

[2] Website: http://www.itsa.org/

[3] Shladover, S.E, "Automated vehicles for highway operations", Journal of Systems and Control Engineering, 2005, Sage; doi: $10.1243 /$

[4] Aldona Jarašūnienė, "ANALYSIS OF POSSIBILITIES AND PROPOSALS OF INTELLIGENT TRANSPORT SYSTEM (ITS) IMPLEMENTATION IN LITHUANIA", TRANSPORT - 2006, Vol XXI, No 4, 245-251, Taylor \& Francis; DOI: 10.1080/16484142.2006.9638074

[5] Todd Goldman, Roger Gorham, "Sustainable urban transport: Four innovative directions", Technology in Society 28 (2006) 261-273, Elsevier; doi:10.1016/j.techsoc.2005.10.007

[6] Eva Gustafsson and Annika Jonsson, "ALWAYS BEST CONNECTED", IEEE Wireless Communications, February 2003; doi: 10.1109/MWC.2003.1182111

[7] Y.K. Kim, R. Prasad, "4G Roadmap and Emerging Communication Technologies", Artech House, Boston and London, 2006.

[8] J. Korhonen, Introduction to $3 \mathrm{G}$ Mobile Communications, 2/e, ARTECH HOUSE, INC., 2003.

[9] Ekram Hossain, Garland Chow, Victor C.M. Leung, Robert D. McLeod, Jelena Mišic', Vincent W.S. Wong, Oliver Yang, "Vehicular telematics over heterogeneous wireless networks: A survey", Computer Communications

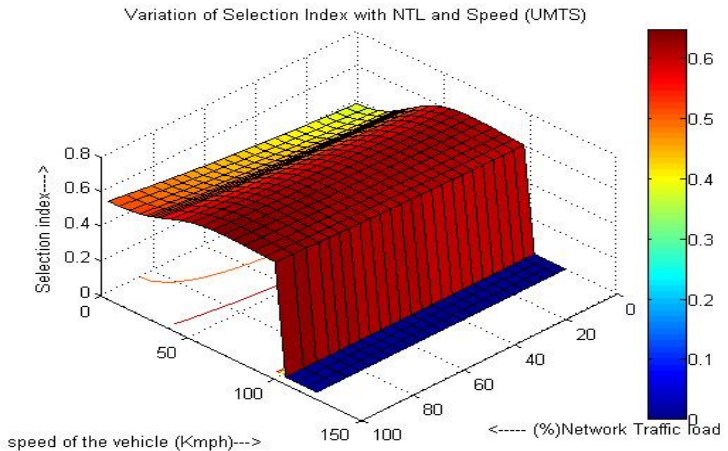

Figure 15. Variation of selection index with NTL and speed (UMTS)

\section{DisCUSSION AND CONCLUSIONS}

Three RANs are taken as alternatives in a virtual road transport scenario. The proposed algorithm is based on very simple mathematics yet considers multiple constraints to select the optimum RAN to ensure seamless connectivity. Evaluation of simple mathematics ensures very less execution time which results in a faster handover. Impacts of both the objective factors (mobile terminal velocity and NTL) are studied on VHO as well as behavior of individual RANs.

The context awareness ensures the adaptability of the proposed algorithm against the changes in the influencing parameters to keep the users' quality of experience (QoE) satisfactory.
33
(2010)
$775-793$
Elsevier; doi:10.1016/j.comcom.2009.12.010

[10] J.Z. Sun, "A review of Vertical Handoff Algorithms for Cross Domain Mobility, International Conference on Wireless Communications, Networking and Mobile Computing", 21-25Sept.2007, Shanghai; DOI: 10.1109/WICOM.2007.782

[11] M. Kassar, B. Kervella, G. Pujolle, An overview of vertical handover decision strategies in heterogeneous wireless networks, Computer Communications 31 (2008) 26072620; Elsevier, doi: 10.1016/j.comcom.2008.01.044

[12] X.Yan, Y.A. Sekerciog lu, S. Narayanan, A survey of vertical handover decision algorithms in Fourth Generation heterogeneous wireless networks, Computer Networks 54 (2010) 1848-1863; Elsevier, doi: 10.1016/j.comnet.2010.02.006

[13] J. Marquez-Barja, C.T. Catafate, J.C. Cano, P. Manzoni, An overview of vertical handover techniques: algorithms, protocols and tools, Computer Communications 34 (2011) 985-997, Elsevier, doi: 10.1016/j.comcom.2010.11.010

[14] P. Goyal, S.K. Saxena, A Dynamic Decision Model for Vertical Handoff across Heterogeneous Wireless Networks, International Journal of Computer Systems Science and Engineering, 5:3 2009; Link: http://www.waset.org/journals/waset/v41/v41-117.pdf

[15] W. Lee, E. Kim, J. Kim, I. Lee, C. Lee, Movement Aware Vertical Handoff of WLAN and Mobile WiMax for seamless Ubiquitous Access, IEEE Transactions on Consumer Electronics, Vol. 53, no. 4, November 2007; DOI: $10.1109 /$ TCE.2007.4429211 
[16] Q. Song, A. Jamilipour, Network Selection in an Integrated Wireless LAN and UMTS Environment Using Mathematical Modeling and Computing Techniques, IEEE Wireless Communications, June 2005; DOI: 10.1109/MWC.2005.1452853

[17] E.S. Navarro, V.W.S. Wong, Comparison between vertical handoff decision algorithms for heterogeneous wireless networks, IEEE 63rd Vehicular Technology Conference, Melbourne, 2006; DOI: 10.1109/VETECS.2006.1682964

[18] Liu Sheng-mei; Pan Su; Xu Ming-hai; “An Improved TOPSIS Vertical Handoff Algorithm for Heterogeneous Wireless Networks",12th IEEE International Conference on Communication Technology (ICCT), 1114 Nov. 2010, Nanjing; doi: 10.1109/ICCT.2010.5688617

[19] Q. Wei, K. Farkas, C. Prehofer, P. Mendes, B. Plattner, "Contextaware handover using active network technology", Computer Networks 50 (15) (2006) 28552872.

[20] T. Ahmed, K. Kyamakya, M. Ludwig, “A context-aware vertical handover decision algorithm for multimode mobile terminals and its performance", in: Proceedings of the IEEE/ACM Euro American Conference on Telematics and Information Systems (EATIS 2006), pp. 19-28.

[21] R. Bera, S. Dhar, D. Kandar, “ Digital Radar for Collision Avoidance and Automatic Cruise Control in Transportation", in proc. Of IEEE ISM 08, 3-6 Dec'08, Bangalore,India;

URL: http://arxiv.org/ftp/arxiv/papers/0903/0903.1509. pdf

[22] R. Bera, D. Mondal, S. Dhar, S. Sil, S.N. Sur, D. Bhaskar, D. Kandar, S.K. Sarkar, "Vehicular Communication and Safety in Realization of Intelligent Transport System", in proc. Of IEEE CODEC 2009, December 14-16, 2009, Kolkata, India; URL: $\mathrm{http}$ ://ieeexplore.ieee.org/xpl/freeabs_all.jsp?arnumber= 5407249

[23] S.Dhar, D. Kandar, P. Karmakar, A. Poddar, R. Bera and M. Chakraborty, "Simulation of Cognitive ShortRange Radar and Imaging of the Moving Target for Safety Application in ITS", in proc. Of IEEE annual conference INDICON 2011, 16-18 December 2011, Hyderabad, India; doi: 10.1109/INDCON.2011.6139458

[24] S.Dhar, A. Poddar, P. Karmakar, T. Paul, D. Kandar and r. Bera, "Radar Target Modeling and 2D ISAR Imaging at $76 \mathrm{GHz}$ for ITS Application", in proc. Of IEEE annual conference INDICON 2011, 16-18 December 2011, Hyderabad, India; doi: 10.1109/INDCON.2011.6139459

[25] R. Bera, S. Sil, S. Dhar and S. K. Sarkar (2008), "Wi-Fi, WiMax and WCDMA A comparative study based on Channel Impairments and Equalization method used" in proc. Of International Symposium on Microwave, December 2008, Bangalore, India; URL: http://arxiv.org/ftp/arxiv/papers/0903/0903.1506.pdf

[26] S.Dhar, R.Bera, R.B. Giri, S.Anand, D.Nath, S.Kumar (2011), "An Overview of V2V Communication Channel Modeling”, in proceedings of ISDMISC'11, 12-14 April, 2011, Sikkim, India; URL: http://www.ijcaonline.org/proceedings/isdmisc/number1 /3443-isdm 187

[27] S.Dhar, P. Chhetri, T. Paul, R. Dahal, A. sharma and R. Bera, "Comparison of Different Channel Estimation Algorithms from ITS Perspective", in proc. Of IEEE annual conference INDICON 2011, 16-18 December
2011, Hyderabad, India; doi: 10.1109/INDCON.2011.6139475

[28] T.Paul, P.Karmakar and S.Dhar, "Comparative Study of Channel Estimation Algorithms under Different Channel Scenario", International Journal of Computer Applications, vol. 34(7), pp(31-38), November 2011; doi: $10.5120 / 4113-5927$

[29] S. Dhar, A. Ray, R. Bera, Design and Simulation of Vertical Handover Algorithm for Vehicular Communication, International J. of Engg. Sci. and Tech. vol 2,no 10, October,2010

[30] S. Dhar, A. Ray, R. Bera, S.N. Sur, D. Ghosh, A Complete Simulation Of Intra Vehicle Link Through Best Possible Wireless Network, International J. of Comp. and Elect. Engg. vol 2,no 4, August,2010

[31] S. Dhar, A. Ray, S. Chakravorty, R. Bera, Intelligent Vertical Handover Scheme For Utopian Transport Scenario ", Trends in Applied Sciences Research, Vol. 6, Issue. 9, $p p(958-976), 2011$. DoI: $10.3923 /$ tasr.2011.958.976

[32] R. Bera, S. Dhar, D. Kandar, N.B. Sinha, M. Mitra, Modeling and Implementation Of Wireless Embedded System For Intelligent Transport System Application , published in IEEE Region 10 Colloquium and the Third International Conference on Industrial and Information Systems, December 8 -10, 2008, Kharagpur, INDIA.

[33] G.R. Jahanshahloo, F. Hosseinzadeh Lotfi, A.R. Davoodi, "Extension of TOPSIS for decision-making problems with interval data: Interval efficiency", Mathematical and Computer Modelling 49 (2009) 1137-1142

[34] M. Fiedler, L. Isaksson and S. Chevul (2005), "Measurements and analysis of application-perceived throughput via mobile links ", Proceedings of the 3rd Performance modeling and evaluation of heterogeneous networks (PMEDN'05), pp (1-33), IIkley, West Yorkshire

Sourav Dhar was born in 1980 at Raiganj, West Bengal, INDIA. He received B.E from Bangalore institute of Technology and M.Tech from Sikkim Manipal Institute of Technology in the year 2002 and 2005 respectively. Currently working as Associate Professor, Department of E\&C Engineering, Sikkim Manipal University, Sikkim, India. Broadband Wireless Mobile Communication, Remote Sensing and cognitive radio are his area of specializations. $\mathrm{He}$ has published more tan 20 papers in journals and conferences.

Sourav Dhar is the corresponding author and can be contacted at Sourav.dhar80@gmail.com;

Mailing Address: Associate Professor; Dept. of Electronics and Communication; Sikkim Manipal Institute of Technology; Majitar; Rangpo; Sikkim; India; Pin-737136

Shubhajit Datta was born in 1988 at Katihar, Bihar, INDIA. He received B.Tech in E.C.E from Dumkal Institute of Engineering \& Technology in the year 2010. Currently he is a student of M.Tech final year in Sikkim Manipal Institute of Technology, Sikkim, India. Shubhajit Datta can be contacted at rony_slg08@yahoo.com;

Dr. Rabindra Nath Bera was born in 1958 at Kolaghat, West Bengal, INDIA. Received his B. Tech, M. Tech \& Ph.D (Tech) from the Institute of Radiophysics \& Electronics, The University of Calcutta, in the year 
1982,1985 \& 1997 respectively. Currently working as Head of the Deparment, Electronics \& Communication Engineering, Sikkim Manipal University,Sikkim. Microwave/ Millimeter wave based Broadband Wireless Mobile Communication and Remote Sensing is the area of specializations. He has published more than 100 papers in journals and conferences.

Dr. Amitava Ray is an Associate Professor in the Department of Mechanical Engineering at Sikkim Manipal Institute of Technology, Sikkim. He received BE and Ph.D in Production Engineering from Jadavpur University, ME in Production Engineering (specialization in Manufacturing Engineering) from Mumbai University. He has around 15 year's professional experience in industry and teaching and published more than 20 research papers. His research interests include operations management, supply chain management, cost engineering, and applied soft computing. 